\title{
Prognostic role of serum C-reactive protein in patients with advanced-stage NSCLC treated with pemetrexed
}

\author{
O. FIALA ${ }^{1,2, *}$, P. HOSEK ${ }^{2}$, M. PESEK ${ }^{3}$, J. FINEK ${ }^{1}$, J. RACEK ${ }^{4}$, T. BUCHLER ${ }^{5}$, A. POPRACH ${ }^{6}$, K. HEJDUK $^{7}$, R. CHLOUPKOVA ${ }^{7}$, O. SOREJS ${ }^{1}$,

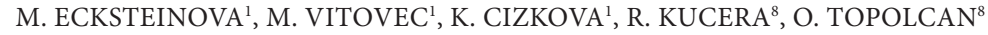

\begin{abstract}
${ }^{1}$ Department of Oncology and Radiotherapeutics, Faculty of Medicine and University Hospital in Pilsen, Czech Republic; ${ }^{2}$ Biomedical Center, Faculty of Medicine in Pilsen, Charles University in Prague, Czech Republic; ${ }^{3}$ Department of Pneumology, Faculty of Medicine and University Hospital in Pilsen, Czech Republic; ${ }^{4}$ Istitute of Clinical Biochemistry and Hematology, Faculty of Medicine and University Hospital in Pilsen, Czech Republic; ${ }^{5}$ Department of Oncology and First Faculty of Medicine, Charles University and Thomayer Hospital, Czech Republic; ${ }^{6}$ Department of Comprehensive Cancer Care, Masaryk Memorial Cancer Institute and Faculty of Medicine, Masaryk University, Brno, Czech Republic; ${ }^{7}$ Institute of Biostatistics and Analysis, Faculty of Medicine, Masaryk University, Brno, Czech Republic; ${ }^{8}$ Department of Nuclear Medicine, Faculty of Medicine and University Hospital in Pilsen, Czech Republic
\end{abstract}

*Correspondence: fiala.o@centrum.cz

Received September 8, 2016/ Accepted January 20, 2017

\begin{abstract}
Pemetrexed is an intravenously administered antifolate cytostatic agent targeting several folate-dependent enzymatic pathways, widely used in the treatment of patients with advanced non-small cell lung cancer (NSCLC). It has been previously demonstrated that the superiority of pemetrexed is limited to patients with non-squamous histology. Aside from the non-squamous histology, there is still no available molecular biomarker predicting treatment efficacy of pemetrexed-based chemotherapy. The aim of our retrospective study was to evaluate the association of baseline serum levels of C-reactive protein $(C R P)$ with outcomes in a large cohort of patients with non-squamous NSCLC treated with pemetrexed. Clinical data of 325 patients were analysed. Serum samples were collected within one week before the initiation of treatment. The median progression-free (PFS) and overall survival (OS) for patients with high CRP was 2.1 and 9.5 compared to 4.2 and 20.5 months for those with normal CRP ( $\mathrm{p}=0.002$ and $\mathrm{p}<0.001$, respectively). The multivariable Cox proportional hazards model revealed that serum CRP $(\mathrm{HR}=1.46, \mathrm{p}=0.002)$ was significantly associated with PFS and also with $\mathrm{OS}(\mathrm{HR}=1.95, \mathrm{p}<0.001)$. In conclusion, the study results suggest that pretreatment serum CRP is associated with poor outcome of non-squamous NSCLC patients treated with pemetrexed.
\end{abstract}

Key words: C-reactive protein, lung cancer, NSCLC, chemotherapy, pemetrexed, prognosis

Lung cancer is one of the leading cancer-related causes of morbidity and mortality in developed countries and its incidence has been still increasing $[1,2]$. Non-small cell lung cancer (NSCLC) is the most common histological type constituting more than $80 \%$ of all lung carcinomas and more than $50 \%$ of them are initially diagnosed with metastatic stage [3]. However, the prognosis of advanced-stage NSCLC patients is adverse, several new effective agents and therapeutic strategies have been approved in recent years and their introduction into the common clinical practice leads to the significant increase of patient survival. Pemetrexed represents one of these effective agents. It is an intravenously administered antifolate cytostatic agent targeting several folate-dependent enzymatic pathways. Randomized phase III clinical trials as well as observational studies have provided evidence for the efficacy and safety of pemetrexed in combination with cisplatin in the first-line and also as a single-agent in the second or third-line treatment for patients with advancedstage non-squamous NSCLC [4-6]. Recently, the phase III clinical trial PARAMOUNT proved efficacy of pemetrexed in the maintenance setting [7]. Using pemetrexed continuation maintenance treatment significantly extended overall survival (OS) of non-squamous lung cancer patients to more than 13 months [7]. However, pemetrexed is an effective agent, there is approximately $20-25 \%$ of patients with primary resistent disease assessed with progressive disease (PD) as the overall response [4-7]. Thus, there is a need for prognostic and predictive biomarkers, feasible for selection of otpimal 
treatment for individual patients. So far, no reliable molecular or genetic biomarker predicting response to pemetrexed in the subgroup with non-squamous NSCLC has been established. The aim of our retrospective study was to evaluate the association of baseline serum levels of C-reactive protein (CRP) with outcomes in a large cohort of patients with non-squamous NSCLC treated with pemetrexed.

\section{Patients and methods}

Patients and treatment. We retrospectively analysed clinical data of 325 patients with cytologically or histologically confirmed locally-advanced (IIIB) or metastatic stage (IV) NSCLC treated with pemetrexed-based chemotherapy. Patients were treated between years 2008 and 2015. Pemetrexed was administered intravenously at the standard approved doses $\left(500 \mathrm{mg} / \mathrm{m}^{2}\right.$ every 3 weeks) in combination with platinum derivative (i.e. cisplatin or carboplatin) as the first-line treatment or in monotherapy as the second or third-line treatment. Dose interruption or reduction was permitted in the event of treatment-related toxicity.

Data source. The clinical registry TULUNG (http://tulung. registry.cz/), in which Faculty Hospital Pilsen is participating since its creation, is a non-interventional post-registration database of epidemiological and clinical data of patients with advanced-stage NSCLC treated with targeted therapies in the Czech Republic. The registry contains anonymised individual patient data including demographic parameters, initial staging and disease characteristics, baseline patient information at the start of targeted therapy, as well as data on survival and adverse events which is updated at least twice a year. Data on

Table 1. Baseline characteristics of patients

\begin{tabular}{llc}
\hline Characteristic & Category & $\boldsymbol{n}(\%)$ \\
\hline Gender & Female & $135(41.5)$ \\
& Male & $190(58.5)$ \\
\hline Age & $<70$ years & $257(79.1)$ \\
& $\geq 70$ years & $68(20.9)$ \\
\hline Smoking & Current smoker & $168(51.7)$ \\
& Former smoker & $94(28.9)$ \\
& Never-smoker & $63(19.4)$ \\
\hline Histology & Adenocarcinoma & $290(89.2)$ \\
& Other & $38(10.8$ \\
\hline Stage & IIIB & $72(22.2)$ \\
& IV & $253(77.8)$ \\
\hline ECOG PS & PS 0 & $38(11.7)$ \\
& PS 1 & $269(82.8)$ \\
& PS 2 & $16(4.9)$ \\
& PS 3 & $2(0.6)$ \\
\hline Line of therapy & 1st line & $135(41.5)$ \\
& 2nd line & $140(43.1)$ \\
& 3rd line & $41(12.6)$ \\
& 4th or higher line & $9(2.8)$ \\
\hline
\end{tabular}

pretreatment serum levels of CRP were extracted from the hospital information system and merged to the registry data. The protocol was approved by the independent ethics committee of the University Hospital Pilsen and complied with the International Ethical Guidelines for Biomedical Research Involving Human Subjects, Good Clinical Practice guidelines, the Declaration of Helsinki, and local laws.

Clinical monitoring. The treatment was prospectively monitored and the clinical course of patients was continuously assessed at specific time points. Clinical follow-up controls including physical examination, plain chest $\mathrm{X}$-ray and routine laboratory tests was performed every 3-4 weeks; computed tomography (CT) or positron emission tomography - (PET)$\mathrm{CT}$ was performed after two or three months of the treatment. The objective tumour response was assessed by the attending physician using Response Evaluation Criteria in Solid Tumours (RECIST) [8].

CRP measurement. Serum samples were collected and the measurement was performed within one week before the initiation of pemetrexed treatment. Serum CRP was measured using immunoturbidimetric method on an AU 2700 or AU 5800 (since 2014) analysers from Beckman Coulter (Brea, CA, USA). The measurements were performed in the central biochemical laboratory at the Department of Clinical Biochemistry, Medical School and Teaching Hospital in Pilsen, using the cut-off value of $10 \mathrm{mg} / \mathrm{l}$, which is the upper boundary of generally accepted norm.

Statistics. Standard frequency tables and descriptive statistics were used to characterize the sample. PFS and OS were estimated using the Kaplan-Meier method and all point estimates were accompanied by $95 \%$ confidence intervals. Progression-free survival (PFS) was defined from the date of the initiation of pemetrexed therapy until the date of first documented progression or death. Overall survival (OS) was defined from the date of the initiation of pemetrexed therapy until the date of death, regardless of its cause. Patients who had not progressed or had not died were censored at the date of last follow-up with respect to their PFS or OS, respectively. Statistical significance of the differences in Kaplan-Meier estimates was assessed using the log-rank test. Multivariable Cox proportional hazards model was used to evaluate the effect of all potential prognostic factors on the survival indicators. Statistical significance of hazard ratios was assessed by means of the Wald test. All reported p-values are two-tailed and the level of statistical significance was set at $\alpha=0.05$. The statistical analysis was performed at the Biomedical Center, Faculty of Medicine in Pilsen, Charles University in Prague using STATISTICA (version $11 \mathrm{Cz}$, StatSoft Inc., Tulsa, OK, USA).

\section{Results}

Baseline serum CRP levels. The study group consisted of 325 patients with histologically or cytologically confirmed advanced-stage (stage IIIB and IV) NSCLC who were treated at Department of Pneumology, Faculty of Medicine and Uni- 


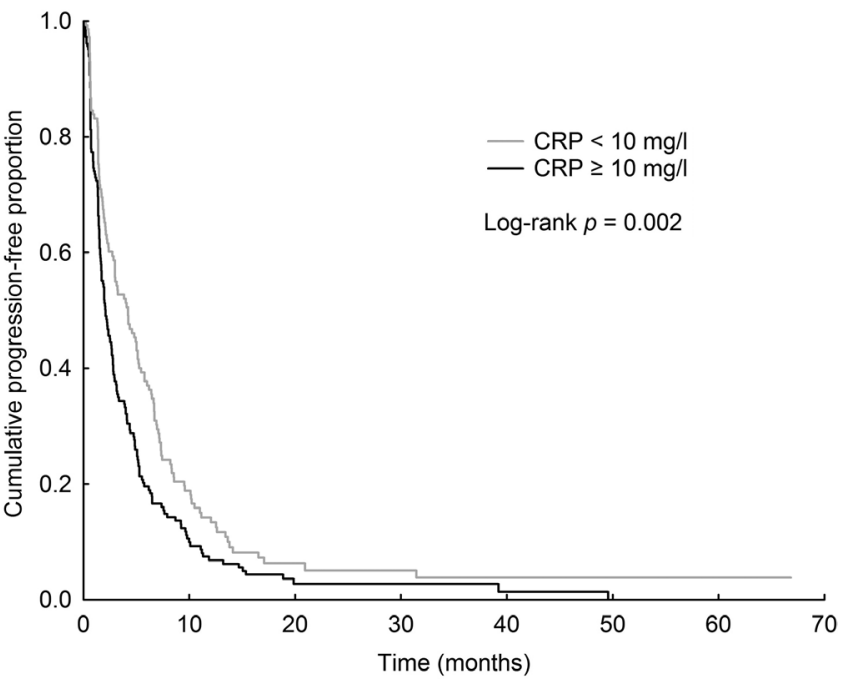

Figure 1. Progression-free survival (PFS) according to baseline serum C-reactive protein (CRP).

versity Hospital in Pilsen between 2008 and 2015. The median age was 64 years (range $=28-83$ years). A total of $190(58.5 \%)$ patients were male, $262(80.6 \%)$ patients had a positive smoking history, $290(89.2 \%)$ patients had adenocarcinoma, 253 (77.8\%) patients had stage IV disease, 307 (94.5\%) patients had an Eastern Cooperative Oncology Group (ECOG) performance status (PS) of 1 or 2 and $135(41.5 \%)$ patients were treated in the first line (with a combination of pemetrexed and platinum derivative). The baseline patient characteristics are summarized in Table 1. Before the treatment initiation, high serum CRP ( $\geq 10 \mathrm{mg} / \mathrm{l}$ ) was measured in 181 (55.7\%) patients and normal levels of CRP $(<10 \mathrm{mg} / \mathrm{l})$ were measured in 144 (44.3\%) patients.

Relation between baseline serum CRP and survival. The median follow-up of the entire cohort was 10.2 months, with 198 deaths. The median PFS was 2.7 months (95\% CI 2.1-3.2), and the median OS was 15.1 months (95\% CI 11.8-16.9).

The median PFS and OS for patients with high serum CRP was 2.1 and 9.5 months compared to 4.2 and 20.5 months for those with normal serum CRP $(p=0.002$ and $p<0.001$, respectively). The 6-month PFS was reached in $37.1 \%$ (28.9-45.2) for

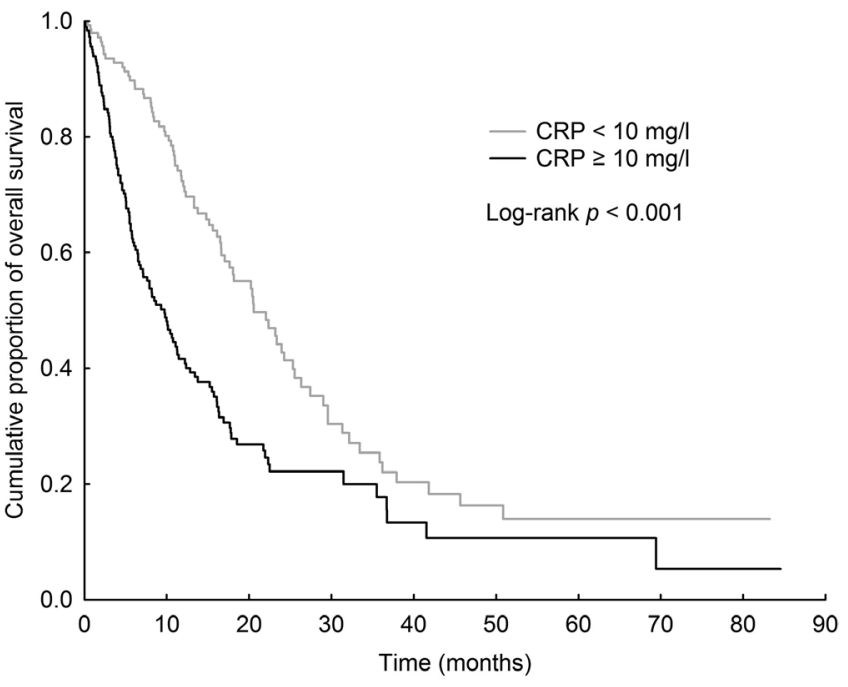

Figure 2. Overall survival (OS) according to baseline serum C-reactive protein (CRP).

patients with high serum CRP compared to $19.3 \%$ (13.5-25.1) for those with normal serum CRP and the The 12-month OS $71.4 \%$ (63.5-79.4) for patients with high serum CRP compared to $41.0 \%$ (33.2-48.9) for those with normal serum CRP. The PFS and OS data are summarized in Table 2 and survival curves are shown in Figure 1. Baseline clinical parameters were assessed together with serum CRP in multivariable model. The multivariable Cox proportional hazards model revealed that serum CRP $(\mathrm{HR}=1.46, p=0.002)$ was significantly associated with PFS and also with $\mathrm{OS}(\mathrm{HR}=1.95, p<0.001)$ (Table 3$)$.

\section{Discussion}

Pemetrexed represents one of novel effective agents which have been approved for the treatment of patients with advanced-stage NSCLC in recent years. It has been previously demonstrated that the superiority of pemetrexed is limited to patients with non-squamous histology $[4,5]$. Aside from the non-squamous histology, there is still no available molecular biomarker predicting treatment efficacy of pemetrexed-based chemotherapy. Several candidate predictive biomarkers

Table 2. Progression-free (PFS) and overall survival (OS) according to C-reactive protein level

\begin{tabular}{|c|c|c|c|}
\hline & \multicolumn{2}{|c|}{ C-reactive protein level } & \multirow{2}{*}{$\begin{array}{c}\text { Log-rank test } \\
p \text { value }\end{array}$} \\
\hline & $<10 \mathrm{mg} / \mathrm{l}(\mathrm{n}=144)$ & $\geq 10 \mathrm{mg} / \mathrm{l}(\mathrm{n}=181)$ & \\
\hline Median PFS (95 \% CI) & 4.2 months $(2.9-5.1)$ & 2.1 months (1.7-2.7) & \\
\hline 3-month PFS (95 \% CI) & $55.6 \%(47.3-63.8)$ & $37.4 \%(30.4-44.5)$ & 0.002 \\
\hline 6-month PFS (95 \% CI) & $37.1 \%(28.9-45.2)$ & $19.3 \%(13.5-25.1)$ & \\
\hline Median OS (95 \% CI) & 20.5 months (16.8-25.3) & 9.5 months (6.7-11.3) & \\
\hline 6-month OS (95 \% CI) & $89.1 \%(83.9-94.4)$ & $61.4 \%(53.9-68.8)$ & $<0.001$ \\
\hline 12-month OS (95\% CI) & $71.4 \%(63.5-79.4)$ & $41.0 \%(33.2-48.9)$ & \\
\hline
\end{tabular}


Table 3. Multivariable Cox-proportional hazards model for progression-free and overall survival

\begin{tabular}{|c|c|c|c|c|c|}
\hline \multirow{2}{*}{ Parameter } & \multirow{2}{*}{ Category } & \multicolumn{2}{|c|}{ Progression-free survival } & \multicolumn{2}{|c|}{ Overall survival } \\
\hline & & HR (95 \% CI) & $p$ value & HR (95 \% CI) & $p$ value \\
\hline \multirow[t]{2}{*}{ CRP } & $<10 \mathrm{mg} / \mathrm{l}$ & 1.00 & & 1,00 & \\
\hline & $\geq 10 \mathrm{mg} / \mathrm{l}$ & $1.46(1.15-1.84)$ & 0.002 & $1.95(1.45-2.61)$ & $<0.001$ \\
\hline \multirow[t]{2}{*}{ Gender } & Female & 1.00 & & 1.00 & \\
\hline & Male & $0.96(0.74-1.24)$ & 0.730 & $1.28(0.94-1.74)$ & 0.115 \\
\hline \multirow[t]{2}{*}{ Age } & $<70$ years & 1.00 & & 1,00 & \\
\hline & $\geq 70$ years & $0.91(0.68-1.21)$ & 0.501 & $0.88(0.62-1.26)$ & 0.489 \\
\hline \multirow[t]{2}{*}{ Smoking } & Never-smoker & 1.00 & & 1,00 & \\
\hline & Current and former smoker & $1.19(0.87-1.64)$ & 0.287 & $1.14(0.78-1.68)$ & 0.489 \\
\hline \multirow[t]{2}{*}{ Histology } & Adenocarcinoma & 1.00 & & 1,00 & \\
\hline & Other & $1.28(0.90-1.82)$ & 0.174 & $1.14(0.75-1.74)$ & 0.544 \\
\hline \multirow[t]{2}{*}{ Stage } & IIIB & 1.00 & & 1,00 & \\
\hline & IV & $1.27(0.96-1.70)$ & 0.098 & $1.23(0.87-1.74)$ & 0.249 \\
\hline \multirow[t]{2}{*}{ ECOG PS } & PS 0 and PS 1 & 1.00 & & 1,00 & \\
\hline & PS 2 and PS 3 & $1.39(0.83-2.31)$ & 0.207 & $1.80(0.99-3.28)$ & 0.055 \\
\hline \multirow[t]{2}{*}{ Line of therapy } & 1st line & 1,00 & & 1,00 & \\
\hline & 2nd or higher line & $1.20(0.94-1.53)$ & 0.148 & $1.15(0.85-1.55)$ & 0.378 \\
\hline
\end{tabular}

including expression of thymidylate synthase, miR-25, miR145 , miR-210 and serum leptin have been studied but not sufficiently validated for the routine clinical use [9-12]. We focused on the association of baseline serum levels of CRP with outcomes in a large cohort of non-squamous NSCLC patients treated with pemetrexed. Serum CRP is a sensitive marker of acute-phase of systemic inflammatory response (SIR), mainly produced by hepatocytes in response to elevated cytokine levels after inflammatory stimulus $[13,14]$. Previously published studies suggested that serum CRP is associated with survival in patients with various malignancies such as gastric [15], colorectal [16], pancreatic [17], ovarian cancer [18] and renal cancer [19] and also NSCLC [20-26].

In the present study including 325 advanced-stage NSCLC patients with non-squamous histology treated with pemetrexed, we observed significantly shorter PFS ( 2.1 vs. 4.2 months, $p=0.002)$ and also OS (9.5 vs. 20.5 months, $p<0.001)$ for patients with high pretreatment serum CRP compared to those with normal levels. The multivariable Cox proportional hazards model confirmed that high pretreatment CRP was independently associated with shorter PFS ( $\mathrm{HR}=1.46$; $p=0.002)$ and $\mathrm{OS}(\mathrm{HR}=1.95 ; p<0.001)$. Our results are in agreement with data previously reported by Koch et al. and Scott et al., who have shown that high pretreatment serum CRP predict poor survival in advanced-stage NSCLC patients treated with palliative chemotherapy and that CRP was an independent prognostic factor $[21,22]$. Moreover, Wilop et al. observed that a change in serum CRP before and after two cycles of chemotherapy was in correlation with outcome and that normalization of CRP was associated with a low risk for progression [23]. Aside from chemotherapy, in our previous work, we observed that high CRP levels also predict poor outcome of advanced-stage NSCLC patients treated with erlotinib, an epidermal growth factor receptor tyrosine kinase inhibitor (EGFR-TKI) [26].

The relationship between inflammation and cancer has been previously demonstrated. Tumour growth can cause tissue inflammation and hence an increase in serum CRP. Cancer cells are known to produce various cytokines including IL-6 and some cancer cells have been shown to express CRP. It has been reported that IL- 6 was the only inflammatory cytokine independently associated with serum CRP concentrations in patients with advanced-stage NSCLC [27]. The data suggest serum CRP as a useful surrogate marker of IL-6 activity in patients with NSCLC. IL-6 is a multifunctional cytokine which plays an important role in a wide range of biologic activities in different types of cell including tumor cells. IL-6 is involved in the host immune defense mechanism as well as the modulation of growth and differentiation in various malignancies. It has been reported that IL- 6 widely contributes to the cancer growth and progression via IL6R-JAK-STAT3 signalling pathway $[28,29]$. STAT proteins are a family of transcription factors that play a key role in various tyrosine kinase signaling pathways [30]. Persistent STAT3 activation is oncogenic and regulates cell-cycle progression, tumour invasion, apoptosis, metastic spread and angiogenesis. It is constitutively activated in a variety of human cancers [29, 30]. Activation of STAT-3 has also been linked with resistance of cancer cells to chemotherapy. Bharti et al. reported that constitutive activation of STAT-3 mediates chemoresistance through the upregulation of various antiapoptotic gene products in metastatic breast cancer cells [31]. The increasing knowledge regarding the molecular biology mechanisms of IL-6 and its interrelations to human cancer has been leading to the development of novel antibody-based therapies. During the last decade, several monoclonal antibodies targeting IL-6 
pathway have been developed, with promising results both in NSCLC $[32,33]$. Based on these data, the results of the present study and also several previously mentioned studies focused on the prognostic role of CRP, we suggest that measurement of serum CRP can identify patients with low response to chemotherapy and also EGFR-TKIs. On the other hand it seems that the measurement of CRP and/or IL-6 serum levels could be a candidate predictive factor for the treatment with new agents targeting the IL- 6 pathway.

The principal limitations of the present study are its retrospective design and relative heterogeneity of the sample including patients treated with combination of pemeterexed with platinum derivative in the first line and those treated with pemetrexed monotherapy in the second or third line. The fact is that it is not always possible to find out whether a CRP elevation is due to intercurrent infection or cancer. On the other hand, we measured CRP in blood samples obtained one day before the start of the treatment and at that time no clinical signs of an infectious disease were present.

In conclusion, the results of the conducted retrospective study suggest that the pretreatment serum CRP is independently associated with PFS and also with OS for advanced-stage NSCLC patients with non-squamous histology treated with pemetrexed-based chemotherapy and that serum CRP provides additional information to the established prognostic factors such as the stage of disease and performance status.

Acknowledgements: The authors would like to thank all patients voluntarily taking part in the observational, population-based registry TULUNG. This study was supported by the National Sustainability Program I (NPU I) Nr. LO1503 provided by the Ministry of Education Youth and Sports of the Czech Republic.

\section{References}

[1] JEMAL A, BRAY F, CENTER MM, FERLAY J, WARD E et al. Global cancer statistics. CA Cancer J Clin 2011; 61: 69-90. https://doi.org/10.3322/caac.20107

[2] FERLAY J, PARKIN DM, STELIAROVA-FOUCHER E. Estimates of cancer incidence and mortality in Europe in 2008. Eur J Cancer 2010; 46: 765-781. https://doi.org/10.1016/j. ejca.2009.12.014

[3] BRAMBILlA E., TRAVIS WD, COLBY TV, CORRIN B, SHIMOSATO Y. The new World Health Organization classification of lung tumours. Eur Respir J 2001; 18: 1059-1068. https://doi.org/10.1183/09031936.01.00275301

[4] SCAGLIOTTI GV, PAIKH P, von PAWEL J, BIESMA B, VANSTEENKISTE J et al. Phase III study comparing cisplatin plus gemcitabine with cisplatin plus pemetrexed in chemotherapy naive patients with advanced-stage non-small-cell lung cancer. J Clin Oncol 2008; 26: 3543-3551. https://doi.org/10.1200/ ICO.2007.15.0375

[5] HANNA N, SHEPHERD FA, FOSSELLA FV, PEREIRA JR, De MARINIS F et al. Randomized phase III trial of pemetrexed versus docetaxel in patients with non-small-cell lung cancer previously treated with chemotherapy. J Clin Oncol 2004; 22: 1589-1597. https://doi.org/10.1200/JCO.2004.08.163

[6] RODRIGUES-PEREIRA J, KIM JH, MAGALLANES M, LEE DH, WANG J et al. A randomized phase 3 trial comparing pemetrexed/carboplatin and docetaxel/carboplatin as firstline treatment for advanced, nonsquamous non-small cell lung cancer. J Thorac Oncol 2011; 6: 1907-1914. https://doi. org/10.1097/JTO.0b013e318226b5fa

[7] PAZ-ARES LG, de MARINIS F, DEDIU M, THOMAS M, PUJOL JL et al. PARAMOUNT: Final overall survival results of the phase III study of maintenance pemetrexed versus placebo immediately after induction treatment with pemetrexed plus cisplatin for advanced nonsquamous non-small-cell lung cancer. J Clin Oncol. 2013; 31: 2895-2902. https://doi. org/10.1200/JCO.2012.47.1102

[8] THERASSE P, ARBUCK SG, EISENHAUER EA, WANDERS J, KAPLAN RS et al. New guidelines to evaluate the response to treatment in solid tumours. J Natl Cancer Inst 2000; 3: 205-216. https://doi.org/10.1093/jnci/92.3.205

[9] NICOLSON MC, FENNELL DA, FERRY D, O‘BYRNE K, SHAH R et al. Thymidylate synthase expression and outcome of patients receiving pemetrexed for advanced nonsquamous non-small-cell lung cancer in a prospective blinded assessment phase II clinical trial. J Thorac Oncol 2013; 8: 930-939. https://doi.org/10.1097/JTO.0b013e318292c500

[10] SUN JM, HAN J, AHN JS, PARK K and AHN MJ: Significance of thymidylate synthase and thyroid transcription factor 1 expression in patients with nonsquamous non-small cell lung cancer treated with pemetrexed-based chemotherapy. J Thorac Oncol 2011; 6: 1392-1399. https://doi.org/10.1097/ JTO.0b013e3182208ea 8

[11] SHI SB, WANG M, TIAN J, LI R, CHANG CX et al. MicroRNA 25, microRNA 145, and microRNA 210 as biomarkers for predicting the efficacy of maintenance treatment with pemetrexed in lung adenocarcinoma patients who are negative for epidermal growth factor receptor mutations or anaplastic lymphoma kinase translocations. Transl Res 2016; 170: 1-7. https://doi.org/10.1016/j.trsl.2015.11.006

[12] MOU W, XUE H, TONG H, SUN S, ZHANG Z et al. Prognostic value of serum leptin in advanced lung adenocarcinoma patients with cisplatin/pemetrexed chemotherapy. Oncol Lett 2014; 7: 2073-2078. https://doi.org/10.3892/ ol.2014.1988

[13] GABAY C and KUSHNER I. Acute phase protein and other systemic responses to inflammation. N Engl J Med 1999; 340: 448-454. https://doi.org/10.1056/NEJM199902113400607

[14] VOLANAKIS JE. Human C-reactive protein: expression, structure, and function. Mol Immunol 2001; 38: 189-197. https://doi.org/10.1016/S0161-5890(01)00042-6

[15] SHIMURA T, KITAGAWA M, YAMADA T, EBI M, MIZOSHITA $\mathrm{T}$ et al. C-reactive protein is a potential prognostic factor for metastatic gastric cancer. Anticancer Res 2012; 32: 491-496.

[16] KOIKE Y, MIKI C, OKUGAWA Y, YOKOE T, TOIYAMA $\mathrm{Y}$ et al. Preoperative $\mathrm{C}$-reactive protein as a prognostic and therapeutic marker for colorectal cancer. J Surg Oncol 2008; 98: 540-544. https://doi.org/10.1002/jso.21154 
[17] PINE JK, FUSAI KG, YOUNG R, SHAMA D, DAVIDSON $\mathrm{BR}$ et al. Serum C-reactive protein concentration and the prognosis of ductal adenocarcinoma of the head of pancreas. Eur J Surg Oncol 2009; 35: 605-610. https://doi.org/10.1016/j. ejso.2008.12.002

[18] HEFLER LA, CONCIN N, HOFSTETTER G, MARTH C, MUSTEA A et al. Serum C-reactive protein as independent prognostic variable in patients with ovarian cancer. Clin Cancer Res 2008; 14: 710-714. https://doi.org/10.1158/1078-0432. CCR-07-1044

[19] KARAKIEWITZ PI, HUTTERER GC, TRINH QD, JELDRES C, PERROTTE $P$ et al. C-reactive protein is an informative predictor of renal cell carcinoma-specific mortality: a European study of 313 patients. Cancer 2007; 110: 1241-1247. https://doi.org/10.1002/cncr.22896

[20] HARA M, MATSUZAKI Y, SHIMUZU T, TOMITA M, AYABE T et al. Preoperative serum Creactive protein level in non-small-cell lung cancer. Anticancer Res 2007; 27: 30013004.

[21] KOCH A, FOHLIN H and SORENSON S. Prognostic Significance of C-Reactive protein and smoking in patients with advanced non-small cell lung cancer treated with first-line palliative chemotherapy. J Thorac Oncol 2009; 4: 326-332. https://doi.org/10.1097/JTO.0b013e31819578c8

[22] SCOTT HR, McMILLAN DC, FORREST LM, BROWN DJF, McARDLE CS et al. The systemic inflammatory response weight loss, performance status and survival in patients with inoperable non-small cell lung cancer. Br J Cancer 2002; 87: 264-267. https://doi.org/10.1038/sj.bjc.6600466

[23] WILOP S, CRYSANDT M, BENDEL M, MAHNKEN AH, OSIEKA $\mathrm{R}$ et al. Correlation of $\mathrm{C}$-reactive protein with survival and radiographic response to firstline platinumbased chemotherapy in advanced non-small cell lung cancer. Onkologie 2008; 31: 665-670.

[24] PIRCHER A, ULSPERGER E, HACK R, JAMNIG H, PALL G et al. Basic clinical parameters predict gefitinib efficacy in nonsmall cell lung cancer. Anticancer Res 2011; 31: 2949-2955.

[25] MASAGO K, FUJITA S, TOGASHI Y, KIM YH, HATACHI Y et al. Clinical significance of pretreatment C-reactive protein in patients with advanced nonsquamous, non-small cell lung cancer who received gefitinib. Oncology 2010; 79: 355-362. https://doi.org/10.1159/000323486

[26] FIALA O, PESEK M, FINEK J, TOPOLCAN O, RACEK J et al. High serum level of C-reactive protein is associated with worse outcome of patients with advanced-stage NSCLC treated with erlotinib. Tumour Biol. 2015; 36: 9215-9222. https://doi.org/10.1007/s13277-015-3660-3

[27] MCKEOWN DJ, BROWN DJ, KELLY A, WALLACE AM AND McMILLAN DC. The relationship between circulating concentrations of C-reactive protein, inflammatory cytokines and cytokine receptors in patients with non-small-cell lung cancer. Br J Cancer 2004; 91: 1993-1995. https://doi. org/10.1038/sj.bjc. 6602248

[28] HAURA EB, ZHENG Z, SONG L, CANTOR A and BEPLER G. Activated epidermal growth factor receptor-Stat-3 signaling promotes tumor survival in vivo in non-small cell lung cancer. Clin Cancer Res 2005; 11: 8288-8294. https://doi. org/10.1158/1078-0432.CCR-05-0827

[29] AGGARWAL BB, KUNNUMAKKARA AB, HARIKUMAR KB, GUPTA SR, THARAKAN ST et al. Signal transducer and activator of transcription-3, inflammation, and cancer: how intimate is the relationship? Ann N Y Acad Sci 2009; 1171: 59-76. https://doi.org/10.1111/j.1749-6632.2009.04911.x

[30] BROMBERG JF, WRZESZCZYNSKA MH, DEVGAN G, ZHAO Y, PESTELL RG et al. Stat3 as an oncogene. Cell 1999; 98: 295-303. https://doi.org/10.1016/S0092-8674(00)81959-5

[31] REAL PJ, SIERRA A, De JUAN A, SEGOVIA JC, LOPEZ-VEGA JM et al. Resistance to chemotherapy via Stat3-dependent overexpression of Bcl-2 in metastatic breast cancer cells. Oncogene 2002; 21: 7611-7618. https://doi.org/10.1038/ sj.onc. 1206004

[32] KIM NH, KIM SK, KIM DS, ZHANG D, PARK JA et al. Anti-Proliferative action of IL-6R-targeted antibody tocilizumab for non-small cell lung cancer cells. Oncol Lett 2015; 9: 2283-2288. https://doi.org/10.3892/ol.2015.3019

[33] SONG L, SMITH MA, DOSHI P, SASSER K, FULP W et al. Antitumor efficacy of the anti-interleukin-6 (IL-6) antibody siltuximab in mouse xenograft models of lung cancer. J Thorac Oncol 2014; 9: 974-982. https://doi.org/10.1097/ ITO.0000000000000193 